\title{
Early and late allergic reaction in the nose assessed by whole body plethysmography
}

\author{
M.S. de Bruin-Weller*+, F.R. Weller+, A. Scholte*, L.H.M. Rijssenbeek*, \\ S. van der Baan**, J.M. Bogaard*++, J.G.R. de Monchy*\#
}

Early and late allergic reaction in the nose assessed by whole body plethysmography. M.S. de Bruin-Weller, F.R. Weller, A. Scholte, L.H.M. Rijssenbeek, S. van der Baan, J.M. Bogaard, J.G.R. de Monchy. (C) ERS Journals Ltd 1996.

ABSTRACT: Physiological changes during late phase nasal responses after allergen challenge are difficult to establish and different criteria are used for the definition of a positive late phase nasal reaction. The objective of this study was to assess the value of whole body plethysmography in detecting changes in nasal airway resistance after allergen challenge and to suggest criteria for the definition of early and late phase nasal reactions.

Nasal challenge with allergen was performed in 15 allergic patients. Nasal resistance was followed until $\mathbf{1 0} \mathrm{h}$ after allergen challenge and on a control day using whole body plethysmography.

The mean percentage changes in the inspiratory nasal resistance during the early phase period $(0.25-2 \mathrm{~h})$ and the late phase period $(4-10 \mathrm{~h})$ were significantly higher on the allergen challenge day than on the control day $(p=0.001$ and $p=0.01$, respectively). The mean percentage change in the inspiratory nasal resistance during the early and late phase period on the control day plus 2 times the standard deviation served as cut-off point for a positive reaction. Using this definition, all patients had early reactions and 7 of the 15 patients $(47 \%)$ also had late reactions.

We conclude that whole body plethysmography is a useful, noninvasive method for the measurement of the physiological changes in the nose following allergen challenge.

Eur Respir J., 1996, 9, 1701-1706.

\begin{abstract}
*Asthmacentre Heideheuvel, Hilversum, The Netherlands. +Dept of Pulmonology, Academic Medical Centre, Amsterdam, The Netherlands. **Dept of ENT, University Hospital of Utrecht, The Netherlands. ${ }^{+}$Dept of Pulmonology, University Hospital Dijkzigt, Rotterdam, The Netherlands. \#Dept of Allergology, University Hospital of Groningen, The Netherlands.
\end{abstract}

Correspondence: M.S. de Bruin-Weller Asthmacentre Heideheuvel

Soestdijkerstraatweg 129

1213 VX Hilversum

The Netherlands

Keywords: Allergic reaction

nose

whole body plethysmography

Received: August 81995

Accepted after revision January 271996

This study was financially supported by the Stichting Astma Bestrijding (SAB), The Netherlands and ALK Benelux.
Allergen challenge in the nose in allergic patients often results in an early reaction. This reaction can be detected by various clinical methods, such as evaluation of symptom scores, rhinomanometry and peak inspiratory nasal flow [1-4]. The early reaction can also be detected by the influx of inflammatory cells in nasal secretions [5, 6], or by an increased level of mediators, such as histamine, prostaglandin $\mathrm{D}_{2}\left(\mathrm{PGD}_{2}\right)$, p-toluenesulfonylL-arginine methylester (TAME) esterase activity and kinins in nasal lavage fluid $[7,8]$.

Nasal late phase reactions have been reported in 3-75\% of allergen-challenged allergic patients [8-13]. In contrast to the late phase bronchial reaction, no clear criteria have been developed for the definition of the late nasal response. Although many authors have described histological and biochemical changes during late nasal response $[8,14,15]$, the follow-up of the late nasal response using physical methods has appeared to be very difficult. In contrast to the changes during the early nasal response, the changes in nasal obstruction during late nasal response are quite subtle. The influence of various factors, such as nasal cycle, posture and unphysiological stimulation by nasal instruments, can disturb the registration of the late nasal response [16, 17].

This is the first study in which the early and late reactions after nasal allergen challenge were monitored with whole body plethysmography. The aim of the study was to assess the value of whole body plethysmography in detecting changes in nasal resistance after allergen challenge. Furthermore, criteria for the definition of early and late phase nasal reactions are suggested and discussed.

\section{Patients and methods}

\section{Patients}

Fifteen atopic, nonsmoking patients with rhinitis (5 males and 10 females; aged 21-55 yrs) participated in the study. Twelve of the 15 patients also had asthma; and 10 patients regularly used inhaled steroids. The clinical data are presented in table 1 . Three patients had positive skin tests $(\geq++)$ and/or elevated specific immunoglobulin E (IgE) (Pharmacia Cap $>0.7$ Phadebas radioallergosorbent test (RAST) units (PRU) $\left.\mathrm{mL}^{-1}\right)$ to house-dust mite (HDM), and 12 to grass pollen (GP). The pollen allergic patients were tested outside the pollen season. None of the patients gave a history of respiratory tract infections in the 6 weeks prior to the study. All patients gave informed consent. The study was approved by the Medical Ethics Committee of Asthmacentre Heideheuvel, The Netherlands. 
Table 1. - Clinical data of the patients studied

\begin{tabular}{|c|c|c|c|c|c|c|c|}
\hline \multirow{2}{*}{$\begin{array}{l}\text { Patient } \\
\text { No. }\end{array}$} & \multirow{2}{*}{$\begin{array}{l}\text { Age } \\
\text { yrs }\end{array}$} & \multirow[t]{2}{*}{ Sex } & \multirow[t]{2}{*}{ Allergy } & \multirow[t]{2}{*}{ Asthma } & \multirow[t]{2}{*}{ Smokers } & \multicolumn{2}{|c|}{ Medication } \\
\hline & & & & & & Rhinitis* & $\begin{array}{l}\text { Asthma** } \\
\mu \mathrm{g}\end{array}$ \\
\hline 1 & 30 & M & HDM & + & - & $\mathrm{S}$ & 800 \\
\hline 2 & 27 & $\mathrm{~F}$ & HDM & + & - & - & 400 \\
\hline 3 & 25 & $\mathrm{~F}$ & HDM & + & - & $\mathrm{S}$ & - \\
\hline 4 & 36 & $\mathrm{~F}$ & GP & - & - & - & - \\
\hline 5 & 23 & M & GP & - & - & - & - \\
\hline 6 & 21 & $\mathrm{~F}$ & GP & + & - & S, A & 800 \\
\hline 7 & 34 & $\mathrm{~F}$ & GP & + & - & - & 100 \\
\hline 8 & 23 & M & GP & + & - & - & 1600 \\
\hline 9 & 23 & $\mathrm{~F}$ & GP & + & - & - & 800 \\
\hline 10 & 21 & $\mathrm{~F}$ & GP & + & - & S,A & 1000 \\
\hline 11 & 42 & $\mathrm{~F}$ & GP & - & - & S,A & 200 \\
\hline 12 & 55 & M & GP & + & - & - & 1000 \\
\hline 14 & 23 & M & GP & + & - & $\mathrm{S}$ & 400 \\
\hline 15 & 34 & $\mathrm{~F}$ & GP & + & - & - & - \\
\hline
\end{tabular}

*: medication used for rhinitis; **: dose of inhaled steroids. M: male; F: female; HDM: house-dust mite; GP: grass pollen; S: nasal steroids; A: antihistamines.

\section{Nasal challenge}

Allergen solutions were prepared from stock solutions of Dermatophagoides pteronyssinus and mixed grass pollens, diluted in phosphate-buffered saline (PBS) with $0.03 \%$ human serum albumin and containing $0.0125 \%$ benzalkonium chloride (SQ 503 resp. SQ 293; ALK Benelux), to produce a range of 10 fold increasing concentrations from 100 to 10,000 biological units $(\mathrm{BU}) \cdot \mathrm{mL}^{-1}$. The allergen solutions were administered with a pump spray, delivering a volume of $0.102 \mathrm{~mL}$ (ALK Benelux). Both nostrils were challenged. Before allergen challenge, patients waited 15 min to allow the nasal mucosa to become acclimatized. Increasing doses of allergen were given at 15 min intervals; no further dose was given when the nasal resistance, measured with whole body plethysmography (see below), had doubled. Following the final dose, nasal resistance was measured after $15 \mathrm{~min}$ and thereafter every hour until $10 \mathrm{~h}$ after challenge. On a control day, nasal resistance was recorded until $10 \mathrm{~h}$ after the inhalation of a control solution, a phosphate buffer solution with $0.03 \%$ human serum albumin and containing $0.0125 \%$ benzalkonium chloride.

On the allergen challenge day and on the control day, the mean percentage changes in inspiratory nasal airway resistance compared to preinhalation, in the periods $0.25-2 \mathrm{~h}$ and $4-10 \mathrm{~h}$ post inhalation, were calculated in order to characterize early and late allergic reaction.

\section{Whole body plethysmography}

Whole body plethysmography is often used to determine airway resistance in routine practice [18]. In this study, a volume constant body plethysmograph (Jaeger, Wuerzburg Germany) was used. In this procedure airway resistance $(R \mathrm{aw})$ is measured with open airways (mouth open), and is defined as the quotient of mean alveolar pressure $(\bar{P} \mathrm{~A})$ and the corresponding gas flow $\left(V^{\prime}\right)$ so that $R$ aw $=P \mathrm{~A} / V^{\prime}$. The gas flow is measured at the mouth with a pneumotachometer. The conversion factor for the determination of alveolar pressure from box pressure fluctuations follows from measurements of mouth pressure and box pressure changes during panting through the mouth against a closed shutter. Mouth pressure in conditions of no flow is then considered to be equal to alveolar pressure.

For the measurement of nasal resistance with whole body plethysmography, the mouthpiece, connected to the pneumotachometer, was replaced by a solid nasal mask (nasal continuous positive airway pressure (CPAP) mask). The mask was supported by both of the patient's hands, ensuring that the mask was fixed on the face of the patients without leakage of air, and preventing the patient from blowing out the cheeks. The patients were instructed to breathe quietly through the nose, keeping the mouth closed. Nasal flow through both nostrils was recorded. When five reproducible measurements of nasal flow were recorded, $P$ A was determined by the manoeuvre described above. Nasal resistance $(R \mathrm{n})$ in both nostrils was then calculated from the nasal flow and the $P$ A, according to the formula $R \mathrm{n}=P \mathrm{~A} / V^{\prime} \mathrm{n}$.

In contrast to the pattern of the $P A-V^{\prime}$ curve during measurement of airway resistance, the S-shape of the $P$ aw- $V^{\prime}$ diagram of the nose is most pronounced in the inspiratory phase: during inspiration the patency of the nose is less than during expiration and more sensitive for detection of nasal obstruction due to allergen challenge. Therefore, the inspiratory nasal resistance $(R \mathrm{n}$,insp) was used for the monitoring of the allergic reaction. The initial value of $R$ n,insp on the control day and on the allergen challenge day was considered as $0 \%$. The other values of $R \mathrm{n}$,insp were expressed as percentage changes compared to the initial value.

\section{Rhinomanometry}

Active anterior rhinomanometry was performed with a rhinomanometer, developed by Bachmann (Nasaltest WB; NT-Vertrieb, Mannheim Germany). Nasal flow $\left(\mathrm{mL} \cdot \mathrm{s}^{-1}\right)$ measured at a pressure of $150 \mathrm{~Pa}$ is recorded. Mean flow of both nostrils was used for the follow-up of the allergic reaction.

\section{Peak nasal inspiratory flow}

Peak nasal inspiratory flow was measured with the peak nasal inspiratory flow meter (Youlten, Clement Clarke, London, UK). From three measurements the highest value was recorded. 
Study design

Subjects visited the hospital for two separate days, with at least 3 weeks interval. Medication for the treatment of allergic rhinitis was stopped before the tests: nasal steroids and cromoglycate were stopped 1 week before the tests; antihistamines were stopped $48 \mathrm{~h}$ before the tests. None of the patients received oral corticosteroids or immunotherapy. Inhalation medication for the treatment of asthma was continued.

During the first study day, nasal resistance was registered $15 \mathrm{~min}$ after the inhalation of control solution and after that every hour until $10 \mathrm{~h}$ after the inhalation.

On the second study day, allergen challenge was performed. In all 15 patients, nasal resistance was measured $15 \mathrm{~min}$ after challenge and then every hour until $10 \mathrm{~h}$ after challenge. Measurements were performed at the same time of the day as on the control day. In 11 patients, resistance in the lower airways was also recorded. In 10 patients nasal flow and peak nasal inspiratory flow were also measured.

\section{Data analysis}

The mean percentage change in inspiratory nasal resistance during early and late reaction was compared with the mean percentage change in inspiratory nasal resistance during the same period on the control day, using the Wilcoxon test. Spearman's rank correlation was used for correlation studies. Values are given as mean \pm SD in text and $\pm \mathrm{SD} / \mathrm{SEM}$ as stated in figures. P-values less than 0.05 were considered significant.

\section{Results}

Whole body plethysmography, definition of early and late responses

Figure 1 shows the follow-up of inspiratory nasal resistance $(R \mathrm{n}, \mathrm{insp})$ of 15 patients, measured with whole body plethysmography, both after allergen challenge and during the control day. The initial value of $R$ n,insp on control day $\left(0.63 \mathrm{kPa} \cdot \mathrm{L}^{-1} \cdot \mathrm{s}\right)$ and on allergen challenge day $\left(0.61 \mathrm{kPa} \cdot \mathrm{L}^{-1} \cdot \mathrm{s}\right)$ were defined as $0 \%$. The mean percentage change in $R \mathrm{n}$,insp $\pm \mathrm{SD}$ in the period $0.25-2 \mathrm{~h}$ after allergen challenge (early reaction) was $165 \pm 85 \%$; and in the period $4-10 \mathrm{~h}$ after challenge (late reaction) $46 \pm 50 \%$ (fig. 2).

On the control day, the $R$ n,insp showed minor variation; no effect of challenge with control solution on $R$,insp was found. The mean percentage change in $R \mathrm{n}$,insp \pm SD in the period $0.25-2 \mathrm{~h}$ was $-6 \pm 14 \%$; and in the period 4-10 $\mathrm{h} 1 \pm 14 \%$. When the mean percentage change in $R$ n,insp in the period $0.25-2 \mathrm{~h}$ on the challenge day was compared with the mean percentage change in $R$ n,insp in the same period on the control day a significant difference was found $(\mathrm{p}=0.0007)$. This was also true, although to a lesser extent, during the late phase response $(4-10 \mathrm{~h})$ $(\mathrm{p}=0.007)$.

In order to define the cut-off point for early and late nasal responses, the mean percentage changes in $R$ n,insp on the control day in the above-mentioned periods plus 2sD were calculated (early phase $23 \%$; late phase $29 \%$ ). For practical purposes, an early reaction was defined as

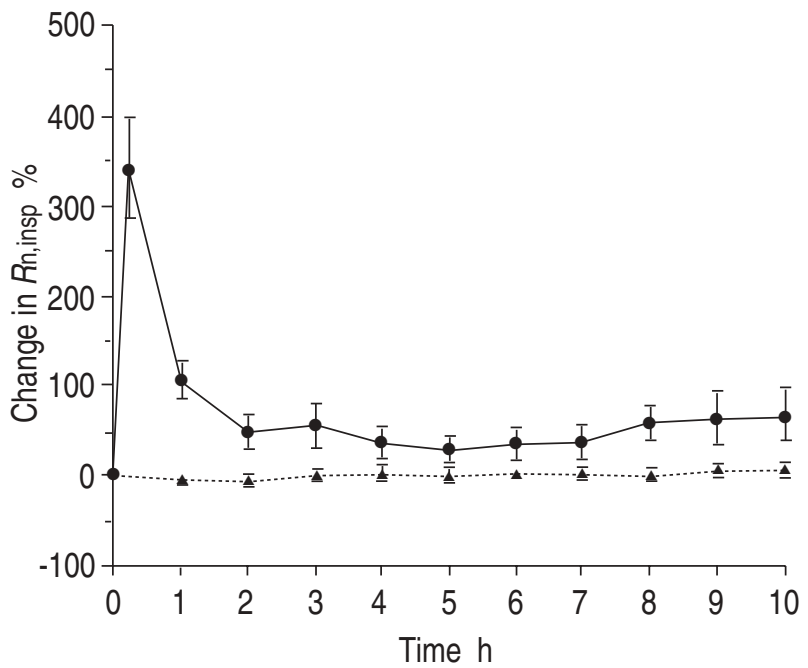

Fig. 1. - Follow-up of inspiratory nasal resistance ( $R$ n,insp) after allergen challenge and on control day in 15 patients. Values are presen-

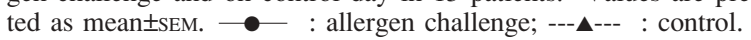

a mean percentage increase in $R \mathrm{n}$,insp $>30 \%$ in the period $0.25-2 \mathrm{~h}$ after challenge, when the $R \mathrm{n}$,insp before challenge was defined as $0 \%$; a late reaction was defined as a mean percentage increase in $R \mathrm{n}$,insp $>30 \%$ in the period 4-10 hours after challenge. When the above-mentioned criteria were used, all 15 patients had early reactions, while seven patients also showed late responses (table 2). We also calculated the number of late responders based on the maximal percentage change in $R \mathrm{n}$,insp in the period 4-10 $\mathrm{h}$ after challenge. On the control day, the mean percentage change in nasal resistance of the 15 patients for each individual time-point during the late phase period $(4-10 \mathrm{~h})$ plus $2 \mathrm{SD}$ was calculated. A cut-off point of $43 \%$ was then found. Ten of the 15 patients had a maximal increase in nasal resistance $>43 \%$ during the late phase period (table 2).

Figure 3 shows the follow-up of airway resistance in the nose and in the lower airways after nasal allergen challenge. No effect of nasal challenge was seen on the airway resistance in the lower airways (inhalation medication was continued).

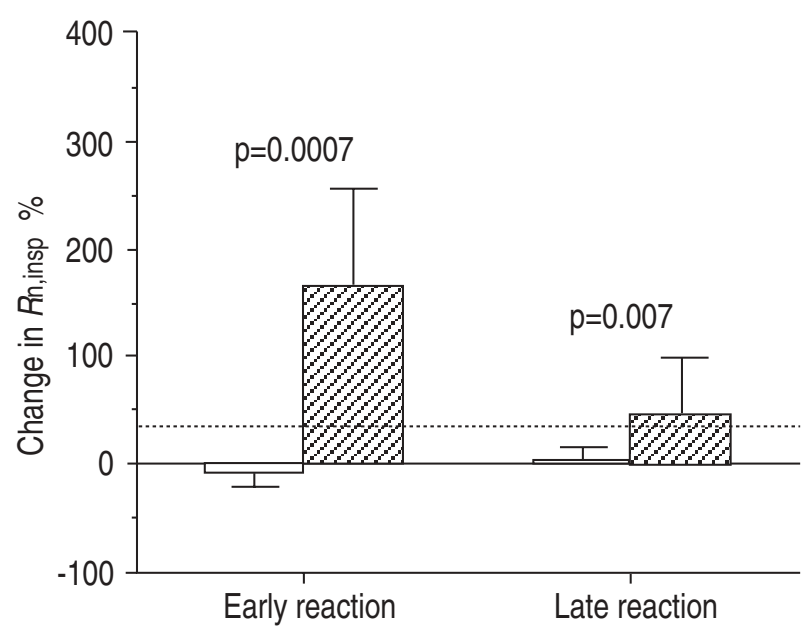

Fig. 2. - Percentage change in inspiratory nasal resistance ( $R$ n,insp) during early and late phase period on allergen challenge day ( $\square$ ) and on control day ( $\square$ ) in 15 patients. Values are presented as mean \pm SD. …….....: cut-off point. 
Table 2. - Change in $R$ n,insp during early and late phase period on control day and on allergen challenge day

\begin{tabular}{|c|c|c|c|c|c|c|}
\hline \multirow[b]{2}{*}{$\begin{array}{l}\mathrm{Pt} \\
\text { No. }\end{array}$} & \multicolumn{2}{|c|}{ Control day } & \multicolumn{4}{|c|}{ Allergen challenge day } \\
\hline & $\begin{array}{c}\text { Mean } \Delta R \mathrm{n} \text {,insp } \\
\text { early response } \\
\%\end{array}$ & $\begin{array}{c}\text { Mean } \Delta R \text { n,insp } \\
\text { late response } \\
\%\end{array}$ & $\begin{array}{c}\text { Mean } \Delta R \mathrm{n} \text {,insp } \\
\text { early response } \\
\%\end{array}$ & $\begin{array}{l}\text { Mean } \Delta R \mathrm{n}, \text { insp } \\
\text { late response } \\
\%\end{array}$ & $\begin{array}{c}\text { Max } \Delta R \text { n,insp } \\
\text { early response } \\
\%\end{array}$ & $\begin{array}{c}\text { Max } \Delta R \mathrm{n}, \text { insp } \\
\text { late response } \\
\%\end{array}$ \\
\hline 1 & -26 & -9 & 283 & $57 *$ & 531 & $157 \#$ \\
\hline 2 & -8 & 5 & 72 & 10 & 106 & 19 \\
\hline 3 & 3 & 23 & 110 & $180 *$ & 195 & $424^{\#}$ \\
\hline 4 & -24 & -25 & 209 & 17 & 454 & 39 \\
\hline 5 & -5 & 0 & 86 & 1 & 227 & 20 \\
\hline 6 & -11 & 12 & 44 & 23 & 120 & $61^{\#}$ \\
\hline 7 & 0 & 7 & 116 & $47 *$ & 160 & $88^{\#}$ \\
\hline 8 & 15 & 18 & 119 & 17 & 323 & $68^{\#}$ \\
\hline 9 & 0 & -1 & 181 & $103 *$ & 233 & $176^{\#}$ \\
\hline 10 & -33 & -4 & 215 & $70 *$ & 410 & $110^{\#}$ \\
\hline 11 & 2 & -7 & 206 & $71 *$ & 440 & $169^{\#}$ \\
\hline 12 & 0 & 5 & 378 & $78 *$ & 900 & $321^{\#}$ \\
\hline 13 & 18 & 12 & 183 & -2 & 504 & 38 \\
\hline 14 & -1 & -2 & 100 & -16 & 251 & 2 \\
\hline 15 & -14 & -26 & 175 & 28 & 256 & $54^{\#}$ \\
\hline Mean & -6 & 1 & 165 & 46 & 341 & 116 \\
\hline SD & 14 & 14 & 88 & 50 & 207 & 119 \\
\hline
\end{tabular}

*: late responder, defined as mean increase in $R_{\mathrm{n}}$,insp $(4-10 \mathrm{~h})>30 \%$; \#: late responder, defined as maximum increase in $R_{\mathrm{n}}$,insp $(4-10 \mathrm{~h})$ at an individual time-point $>43 \%$. Pt: patient; $R$ n,insp: inspiratory nasal resistance.

In order to study whether the use of inhaled steroids in the asthmatic patients could have influenced the intensity of the allergic reaction in the nose, the relationship between the dose of inhaled steroids and the intensity of early and late allergic reaction was studied, calculated as mean percentage increase in $R \mathrm{n}$,insp, in the nose. However, no significant (inverse) correlation could be found (early reaction: $\mathrm{r}=0.05, \mathrm{p}=0.92$; late reaction: $\mathrm{r}=-0.20, \mathrm{p}=0.39)$.

\section{Comparison with rhinomanometry and peak nasal inspi- ratory flow}

In 10 patients, the nasal reaction to allergen challenge was registered using three methods: whole body plethysmography $(R \mathrm{n}, \mathrm{insp})$; active anterior rhinomanometry

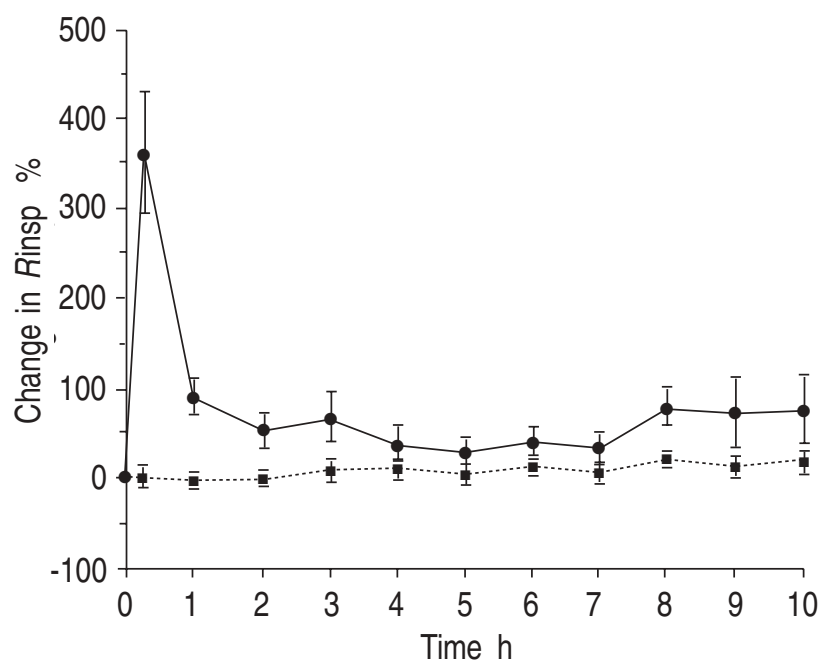

Fig. 3. - Follow-up of inspiratory airways resistance ( $R$ insp) measured in the nose $(n=11)$ and in the lower airways $(n=11)$ after allergen challenge in the nose. Values are presented as meantsem. $-\bullet$ : nose; ........ : lower airways. (mean flow); and peak nasal inspiratory flow (peak flow). Figure 4 shows the results. The early reaction was registered with all three methods. When the nasal early response was defined as the percentage change in nasal resistance, flow and peak flow in the period $0.25-2 \mathrm{~h}$ after challenge, a significant correlation was found between the intensity of nasal early response measured with whole body plethysmography and active anterior rhinomanometry $(\mathrm{r}=-0.68 ; \mathrm{p}=0.04)$. This was not true when whole body plethysmography was compared with peak nasal inspiratory flow $(\mathrm{r}=-0.08 ; \mathrm{p}=0.81)$.

In the period 4-10 h after challenge, a slight increase in nasal resistance was seen from $7 \mathrm{~h}$ after challenge. This was not paralleled by a decrease in flow or in peak flow (fig. 4). When the late nasal response was defined as the percentage change in resistance, flow and peak flow in the period $4-10 \mathrm{~h}$ after challenge, no significant correlation was found between the intensity of the late nasal response measured with whole body plethysmography and active anterior rhinomanometry $(\mathrm{r}=-0.58$; $\mathrm{p}=0.08$ ), or between whole body plethysmography and peak nasal inspiratory flow $(r=-0.26 ; \mathrm{p}=0.44)$.

\section{Discussion}

In contrast to the lower airways, physiological changes during late nasal responses after allergen challenge are difficult to establish. Furthermore, different criteria are used to define late responses in the nose. In order to detect minor physiological changes in the nose during the late phase period, we used whole body plethysmography, a very sensitive method for the measurement of airway resistance. This method has been used for the follow-up of nasal surgery $[19,20]$, but no other data are available about its use for the follow-up of the allergic reaction in the nose. This technique has the advantage that no mechanical irritation or deformation of the upper 


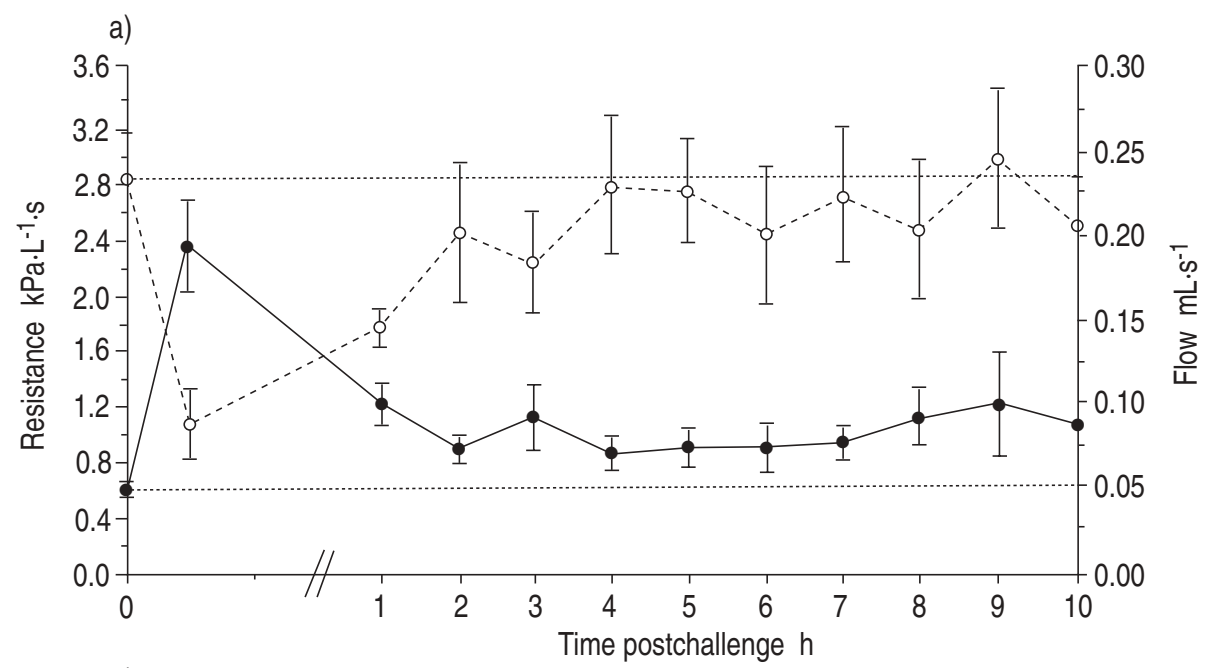

b)

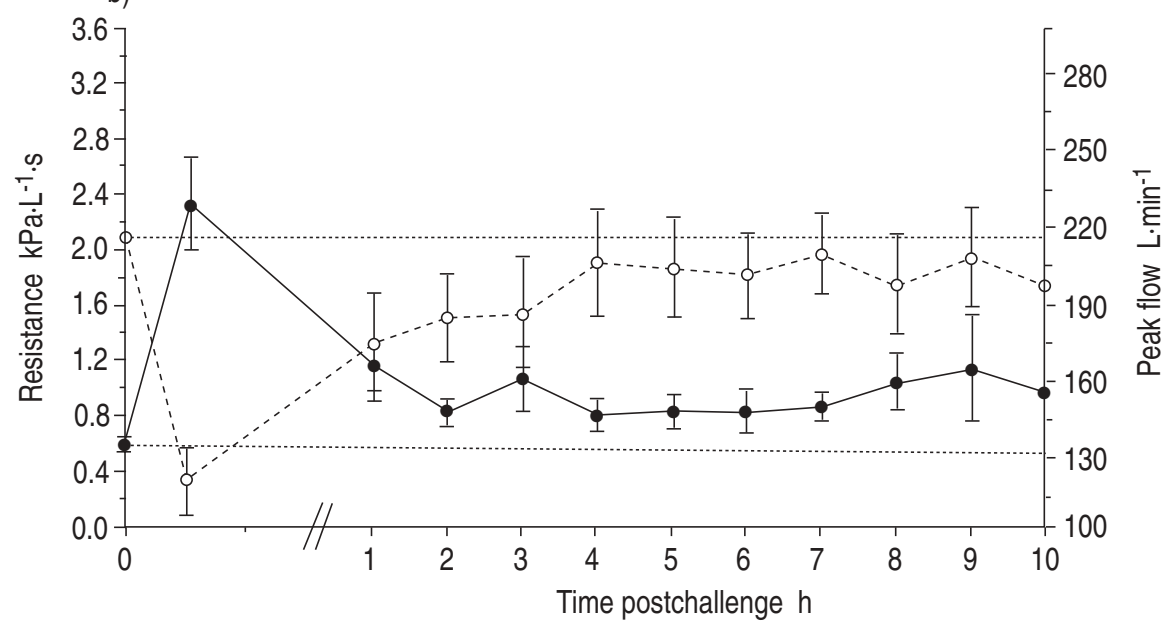

Fig. 4. - a) Follow-up of early and late allergic reaction in the nose using whole body plethysmography and rhinomanometry in 10 patients. b) Follow-up of early and late allergic reactions in the nose using whole body plethysmography and inspiratory nasal peak flow in 10 patients. Values are presented as meantsem. $\longrightarrow-$ : resistance; ----o---- : flow.

airways occurs. Both nostrils are considered as a physiological unit.

On the control day, the variation in nasal resistance measured with whole body plethysmography was small, indicating no interference of disturbing factors. The stable control day and the minor variations in values after repeated measurements at the same time-point indicate a good reproducibility of the method. On the allergen challenge day, the large changes in nasal patency during the early phase period were detected by whole body plethysmography, active anterior rhinomanometry and peak nasal inspiratory flow. The severity of the early nasal response measured with whole body plethysmography showed only a positive correlation with the severity measured with active anterior rhinomanometry. During the quiet period between 4-7 $\mathrm{h}$ after challenge, the standard error of the mean of the $R$ n,insp was relatively small compared to the flow and inspiratory peak flow. During the late phase period, the changes in nasal resistance were relatively small compared to the changes measured during the early phase period, but a significant difference was found between the allergen challenge day and the control day.

The order of challenge (control challenge and allergen challenge) was not randomized in this study, because when an allergen challenge is followed by a control challenge the interval between the two tests should be more than 3 weeks to avoid interference of the allergen challenge on the control challenge. This large interval has the disadvantage that differences in test conditions, especially patients' conditions, could occur between the two test days. To exclude a learning effect, all patients had to be able to produce reproducible values using whole body plethysmography before the tests were started.

In order to define individual early and late responders, the mean percentage changes in $R \mathrm{n}$,insp were calculated in the period $0.25-2 \mathrm{~h}$ and $4-10 \mathrm{~h}$, respectively, on the control day and these value were enlarged by $2 \mathrm{SD}$. When the mean percentage increase in $R \mathrm{n}$,insp on the allergen challenge day during the early or late phase period was above this value $(30 \%)$, patients were defined as early or late responders, respectively. Using this definition, all patients were classified as early responders, and 7 of the 15 patients $(47 \%)$ as late responders.

The number of late responders largely depends on the definition of the late response. In the literature, the maximal percentage change during early and late phase period is often used to define a response. In order to define the number of late responders in the present study based on the maximal percentage increase in nasal resistance 
during late response $(4-10 \mathrm{~h})$, we calculated the mean percentage change in nasal resistance of the 15 patients for each individual time-point on the control day plus 2SD, and found a change of $43 \%$ as cut-off point. After allergen challenge, 10 of the 15 patients had a maximal increase in nasal resistance $>43 \%$ during the late reaction and could be classified as late responders (table 2). Although this definition appears to be mathematically correct, we prefer a definition of the late response based on mean percentage change, because this method is less influenced by outliers and better reflects the intensity of the entire response.

Late phase nasal responses after allergen challenge have been reported in 3-75\% of allergic patients. This variation in reported late reactions depends largely on differences in investigational techniques and different positivity cut-offs [21]. Based on symptom scores and mediator release, NACLERIO et al. [13] reported 75\% late responders. PASTORELli et al. [21] reported a comparable number of late responders as in our study (47\%), using rhinomanometry for the follow-up of the allergic reaction. However, when the definition of a late reaction in the same study was based on symptom scores or on a significant influx of inflammatory cells, the percentage of late responders was 13 and $100 \%$, respectively. In the study by ILIOPOULOS et al. [8], the number of patients with an increased number of inflammatory cells (especially eosinophils) in nasal secretions during the late phase period $(76 \%)$ was larger than the number of patients who were classified as late responders based on mediator release $(47 \%)$, or symptom scores $(45 \%)$. In general, the reported number of late nasal reactions, based on inflammatory changes in the nasal secretions, is higher than the number of late reactions based on physiological methods. It seems that an influx of inflammatory cells in the nose during the late phase period is common in all patients, but these changes are not always detectable with physiological methods.

In the present study, we report on a sensitive, noninvasive method for the follow-up of nasal resistance after allergen challenge. Furthermore, we defined criteria for a positive early nasal reaction and late nasal reaction. Although most of the knowledge concerning early nasal reactions and late nasal reaction is based on cytological and biochemical changes, the detection of physiological changes after allergen challenge may still be relevant. Physiological parameters are usually more closely related to clinical symptoms and because of the noninvasive character of the detection technique, repeated measurements are possible for longitudinal follow-up of the allergic reaction.

We conclude that the method presented is a useful, noninvasive technique for the measurement of physiological changes in the nose following allergen challenge.

Acknowledgements: The authors thank ALK Benelux for the use of the rhinomanometer.

\section{References}

1. Gleeson M, Youlton L, Shelton D, Siodlak M, Eiser N, Wengraf C. Assessment of nasal airway patency: a comparison of four methods. Clin Otolaryngol 1986; 11: 99-107.
2. Druce H. Nasal provocation challenge: strategies for experimental design. Ann Allergy 1988; 60: 191-196.

3. Schumacher M. Rhinomanometry. J Allergy Clin Iтmиnol 1989; 83: 711-720.

4. Druce H, Schumacher M. Nasal provocation challenge: report of the committee on Upper Airway Allergy. $J$ Allergy Clin Immunol 1990; 86: 261-264.

5. Pelikan Z. The changes in the nasal secretions of eosinophils during immediate nasal response to allergen challenge. J Allergy Clin Immunol 1983; 72: 657-662.

6. Pelikan Z, Pelikan-Filipek M. Cytologic changes in the nasal secretions during the immediate nasal response. $J$ Allergy Clin Immunol 1988; 82: 1103-1112.

7. Lebel B, Bousquet J, Morel A, Chanal I, Godard P, Michel F. Correlation between symptoms and the threshold for release of mediators in nasal secretions during nasal challenge with grass pollen grains. J Allergy Clin Immunol 1988; 82: 869-877.

8. Iliopoulos O, Proud D, Adkinson F, et al. Relationship between the early, late, and rechallenge reaction to nasal challenge with antigen: observations on the role of inflammatory mediators and cells. J Allergy Clin Immunol 1990; 86: 851-861.

9. Pelikan Z. Late and delayed responses of the nasal mucosa to the allergen challenge. Ann Allergy 1978; 41: 37-47.

10. Schumacher M, Pain M. Nasal challenge testing in grass pollen hay fever. J Allergy Clin Immunol 1979; 64: 202-208.

11. Richerson H, Rajtora D, Penick G, et al. Cutaneous and nasal allergic responses in ragweed hay fever: lack of clinical and histopathologic correlations with late phase reactions. J Allergy Clin Immunol 1979; 64: 67-77.

12. Dvoracek J, Yunginger J, Kern E, Hyatt R, Gleich G. Induction of nasal late phase reactions by insufflation of ragweed pollen extract. J Allergy Clin Immunol 1984; 73: 363-368.

13. Naclerio R, Proud D, Togias A, et al. Inflammatory mediators in late antigen-induced rhinitis. $N$ Engl J Med 1985; 313: 65-69.

14. Pelikan Z, Pelikan-Filipek M. Cytological changes in the nasal secretions during the late nasal response. $J$ Allergy Clin Immunol 1989; 83: 1068-1079.

15. Varney V, Jacobson M, Sudderick R, et al. Immunohistology of the nasal mucosa following allergen-induced rhinitis. Am Rev Respir Dis 1992; 146: 170-176.

16. Hasgawa M. Nasal cycle and postural variations in nasal resistance. Ann Otol 1982; 91: 112-114.

17. Cole P, Haight J. Posture and nasal patency. Am Rev Respir Dis 1984; 129: 351-354.

18. Dubois A, Botelho S, Bedell G, Marshall R, Comroe J. A rapid plethysmographic method for measuring thoracic gas volume. J Clin Invest 1956; 35: 322-326.

19. Kautzky M, Haber P. Whole body plethysmography studies in patients with deviated nasal septum before and following surgical correction (in German). Wien Medizin Wschr 1987; 103: (Suppl.) 32-34.

20. Kautzky M, Haber P. Body plethysmography studies in patients with obstructed nasal respiration before and following corrective surgery of the nasal septum (in German). Laryngol Rhinol Otol 1988; 65(11): 593-598.

21. Pastorelli E, Riario-Sforza G, Incorvaia C, Segala M, Fumagalli M, Gandini R. Comparison of rhinomanometry, symptom score, and inflammatory cell counts in assessing the nasal late phase reaction to allergen challenge. J Allergy Clin Immunol 1994; 93: 85-92. 